\title{
Developing Edu-Game "Ulun Smart-Kid" Learning Media of Banjar Language and Game Agent with Finite State Machine Model
}

\author{
Reza Andrea \\ Software Engineering Technology, Samarinda State Agricultural Polytechnic, 75131, Indonesia \\ E-mail: reza@politanisamarinda.ac.id
}

\author{
Asep Nurhuda \\ STMIK Widya Cipta Dharma, Samarinda, 75123, Indonesia \\ E-mail: acep.noor@gmail.com
}

Received:22 June 2020; Accepted: 15 July 2020; Published: 08 October 2020

\begin{abstract}
The research entitled edu-game "Ulun Smart-Kid" is a research development of puzzle game type designed to hone memory in the form of language. In this game player must arrange letters in random and create a word in Banjar language. AI technology (artificial intelligence) will also be applied to this research. Using the finite state machine model method game that is built will have game agent character that will accompany a child to play like a teacher. The results of this study make this entitled educational become more interesting and interactive to children. Game agent in the form of teachers can give a sad and happy expression accordingly from the game environment. It accompanies child like a teacher.
\end{abstract}

Index Terms: Ulun Smart-Kid, puzzle game, educational game, finite state machine.

\section{Introduction}

Local content is a subject matter and the introduction of various characteristics of a particular area, not only consisting of skills, crafts, but keeps the cultural manifestations of the local content and custom [1,2]. Learning the local content of Banjar language is intended to maintain the cultural sustainability, also has the identity and personality of the region in addition to national personality [3]. Thus language and cultural preservation is not lost along with the times. Banjar language is the language of the Banjar tribe in South Borneo (Kalimantan, Indonesia) [4,5].

The building of educational game (edu-game) "Ulun Smart-Kid" as a local content of Banjar language and game agent development with Finite State Machine (FSM) model. "Ulun smart kid” means I'm smart kid in Banjar language. It is hoped that the game becomes an interesting place of entertainment and learning and aim to know Banjar language. In this game agent (intelligent agent) will provide action-reactions, observe, and act on a condition so that it looks like yourself, in this game any action or activity built by the agent to meet the environmental conditions [6-8]. Thus in particular occasion the game agent will be implemented with Finite State Machine method (FSM)[6,9], which is a control system design methodology that describes the behavior or working principle of the system by using state, event, and action [10]. Game agent is involved in the form of an animated character that can be expressed from every step of the player. If the player's move is wrong, then the smart agent will be expressed disappointed and vice versa. Identification of problems that exist in this research are, there is no research on how to build a puzzle type edu-game that introduces local content learning about Banjar language. The lack of edu-game that has a child's companion to play in the form of a game agent with AI (artificial intelligence). The objectives of this research are, develop a game of arranging letters (puzzle game) in learning Banjar language, implement finite state machine logic in the form of a frame model to be applied in the game agent character. Testing the questionnaire of beta testing to students and teachers of elementary school to the application of games that are built.

\section{Related Works}

Research on the game with the same technique has been widely done among others:

1. Intelligent Agent Animation of Face For Guessing Word game with Finite State Machine method [11]

2. Game Object Position Scrambling Technique "Find Me! - Earth Etam "[12] 
3. Technically Randomize Arena Game "Find Me! - Earth Etam "with Random Shuffle Technique [13]

In Rachman's research [11], game created implements Finite State Machine method into game agent. The FSM method is used to describe the facial animation expression in commenting on the player's step. The goal of the research is to create intelligent agents that can determine the expressions and comments that should be done by facial animation and apply them to a series of game management "word".

In two game research Find Me! [12,13], the player must find where the funny character object "Nguk-Nguk" is hiding The hiding arena of this cute character cannot be arranged in a regular level sequence, as this will definitely make the game monotonous and boring. Arranging the order of the arena to be faced by player in each level, should be done by random shuffle randomization technique, with the aim of making the game more challenging.

Differences in this study, the game that sharpens the player's ability to think quickly finds and compiles letters into a Banjar language word, letters or objects in the game is randomized using random shuffle positioning randomly to make the game un-static and boring. The game to be built also applies Finite State Machine, where the role of child companion will be replaced with the presence of game agent. Game agents are intelligently controlled game characters using the Finite State Machine thinking logic model (FSM).

\section{Methodology}

Research will be conducted through several stages of multimedia development as follows [6,9,14-16]

1. Study literature about edu-game making process and application of algorithm used, and collect game making materials.

2. Edu-game development process with multimedia system development method, from design to assembly stage of FSM into game system.

3. Installing edu-game apps into children's smartphones and elementary school teachers.

4. Conduct beta testing in the form of questionnaires to children and elementary teachers and review the documents.

5. Analyzing the results of the questionnaire and the review of the application of FSM algorithm in edu-game.

6. Distribution and re-analysis until the test results produce a satisfactory percentage value.

Each step is done sequentially from the first step to the last step, every step that has been done must be reviewed, listed in the framework of research as follows (see figure.1)

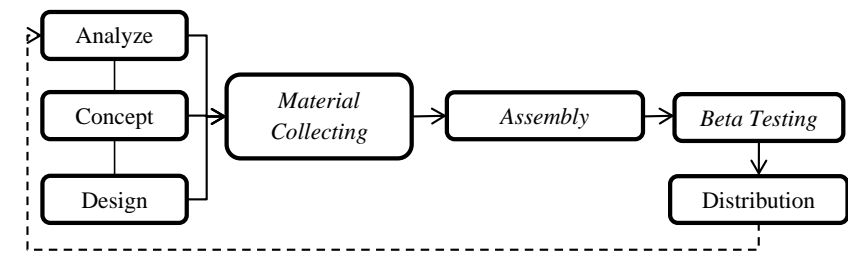

Fig 1. Research Framework

The FSM design is based on events that occur in the child's activity log while playing. The timing and number of picture puzzles are matched to the priority framework of state FSM character agent behavior. FSM characters are designed with different frameworks for each learning and game menu, this is done to create an agent can act as the best companion possible. Below in figure 2 is a state design on Finite State Machine that will be applied to the character agent

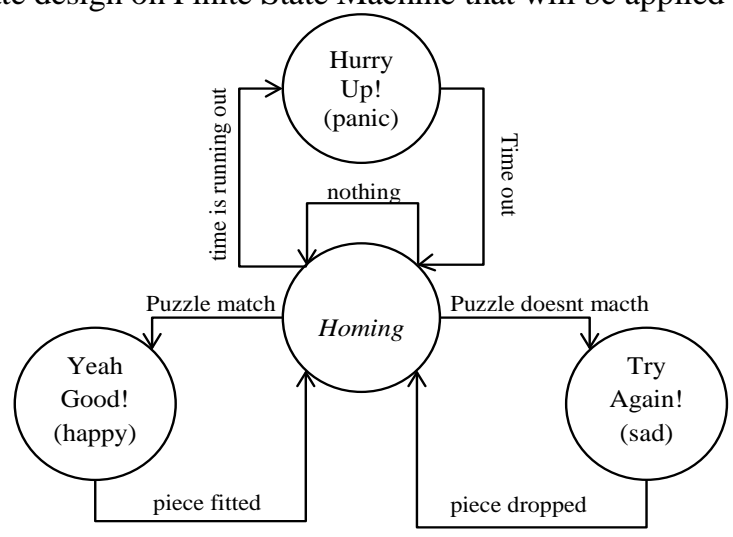

Fig 2. FSM models of game agent

The above model explains that at the beginning of the game, the character (agent) who became the student companion played in a state of idle (homing). The character will move in response to the child's play style when matching the letter of the puzzle. At the time the letter puzzle match, then the character will give a happy response, otherwise when not suitable, 
then the character will give a sad response and still give the spirit to find other letters. The last condition is when the time is running out, the character agent will give a panic response and give the reminder that time is running out

\section{Result and Discussion}

Ulun Smart-Kid learning media local content of Banjar language is an educational game that comprises a category of puzzle game that can invite players to play while learning in a relaxed, easy to learn or played by player. The concept of this game has simple rules and displays content designed for its users for all ages, especially children. This game has four menu options in the scene opening of learning, play, and also the exit menu,

This Edu-game has a rule of play that the player must match the letters and put it on the empty box according to the image of the matter or the word and is changed into spelling in Banjar language, there is time in every stage of the game which can train the speed in remembering words in Banjar and there is also a score in every game that has been played. This concept was assembled to interface on figure.3. This Application was built in 2 languages, there are in English and Bahasa Indonesia Language. Player can choose it in opening scene. In this scene, player can share this game to social media Facebook and Twitter, and player can press setting button to set volume sound Fx and music.

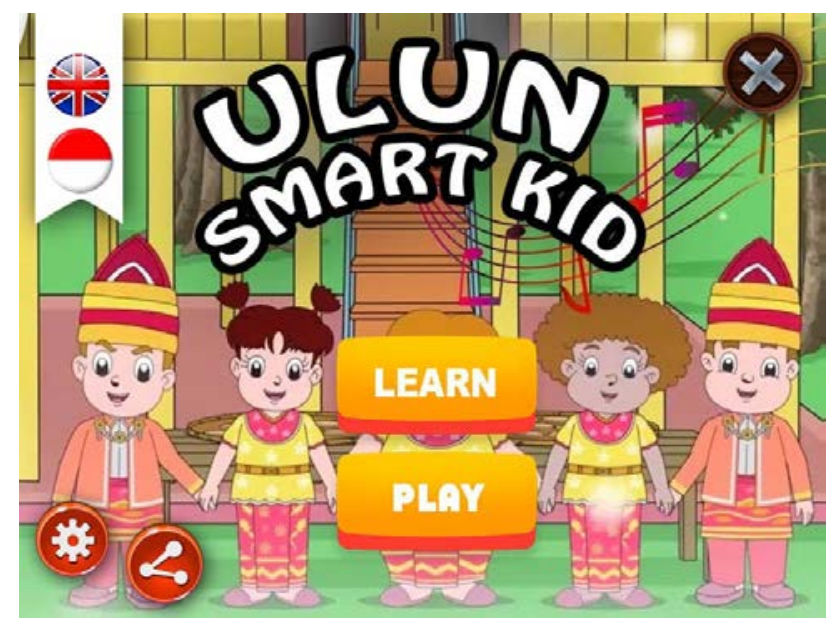

Fig 3. Opening Scene

In learning menu (figure 4), player will learn about words in Banjar language bases made in table similar to language dictionaries. Player can learn 100 Banjar words in this application. player can translate Banjar language to English and Bahasa Indonesia language, and vice versa. Player can search Banjar, English, and Indonesia words by press search button.

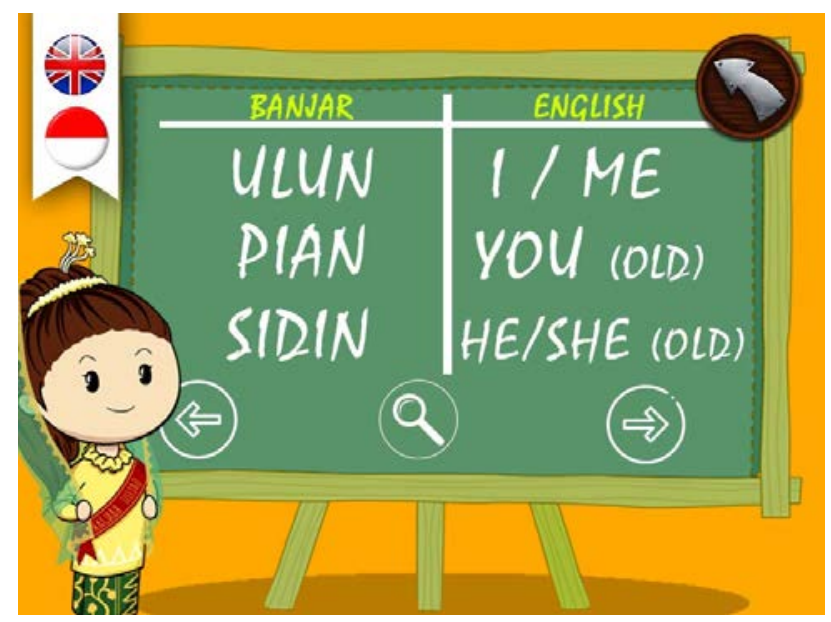

Fig 4. Learning Scene

To start the game, the player must press the play button. In the game there is a time limit of 30 seconds matching a letter object consisting of several letters puzzle boxes (see figure 5). If the player runs out of time before completing the game, then players can choose to repeat or return to the main menu by press setting button. Every level also available in 2 version languages, there are English and Bahasa Indonesia language. 


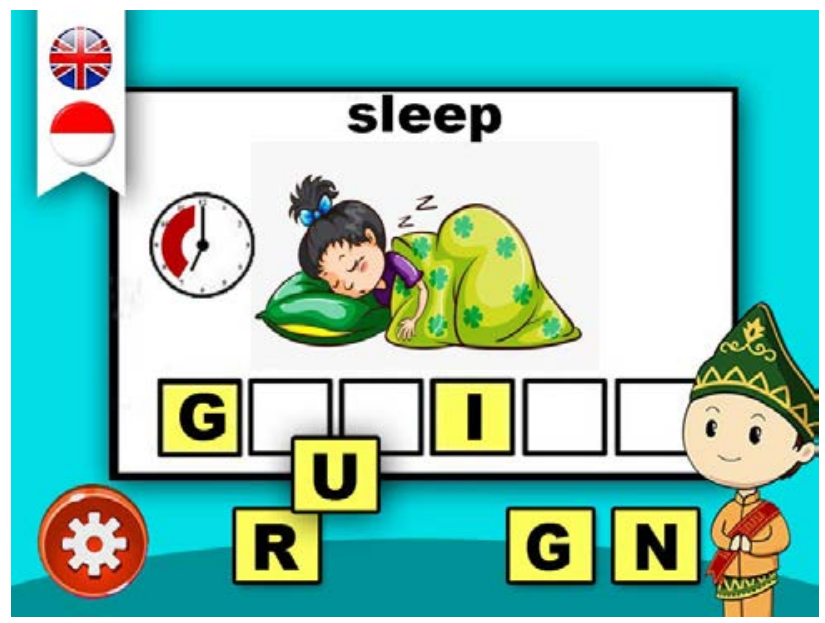

Fig 5. Gameplay

\section{A. Assembly Finite State Machine}

The FSM model (figure 6) is applied as a funny character expression pattern on the game, the funny character will give notification and speak if the player is wrong or correctly match the puzzle, and give notification when time is running out.

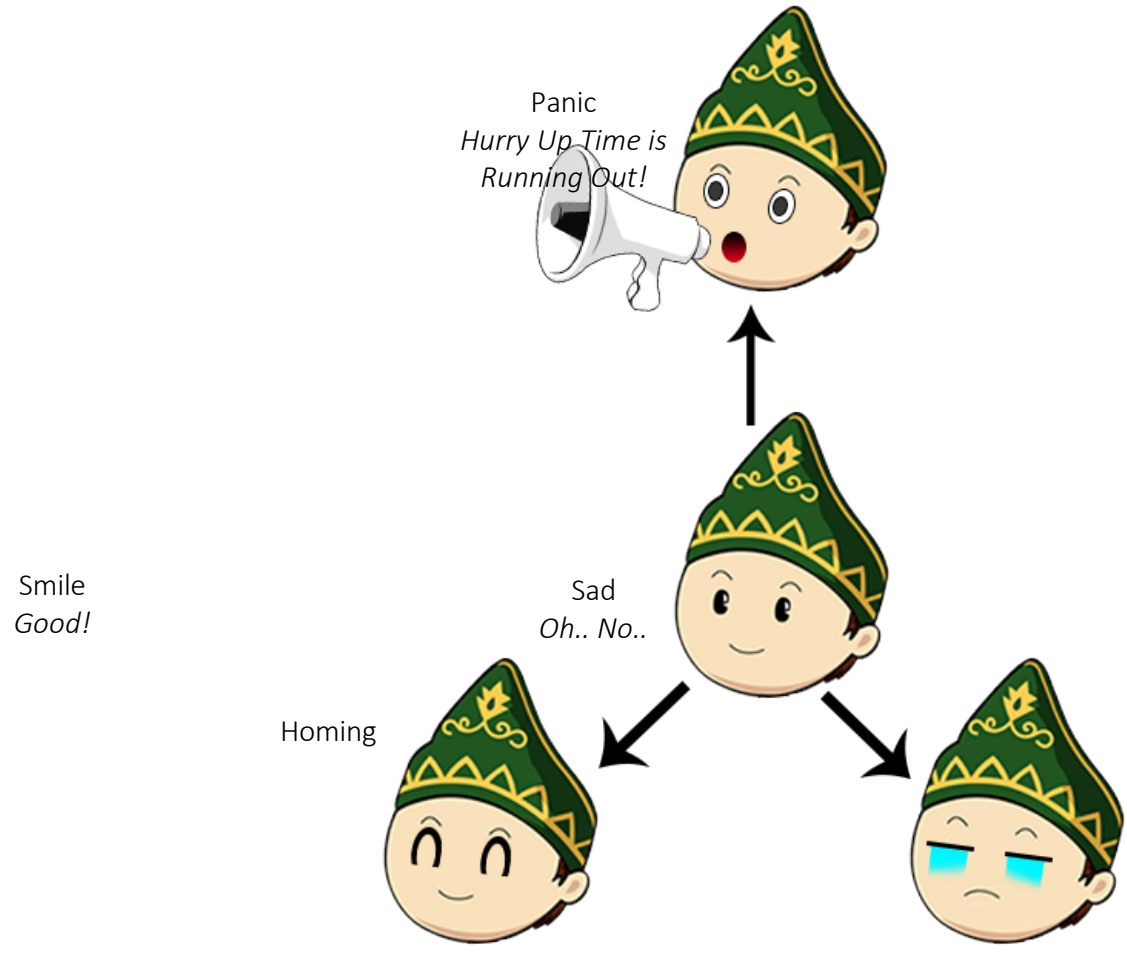

Fig 6. Emoticon of game character

Can be seen in fig.6 above, the character can give a sad, happy, or panic expression when the time is running out. The FSM logic will make this notification appear appropriate from the actions the player performs. The funny characters can also talk to give voice notifications like play companion teacher. Characters can also happy when a player win in this level (see figure 7) 


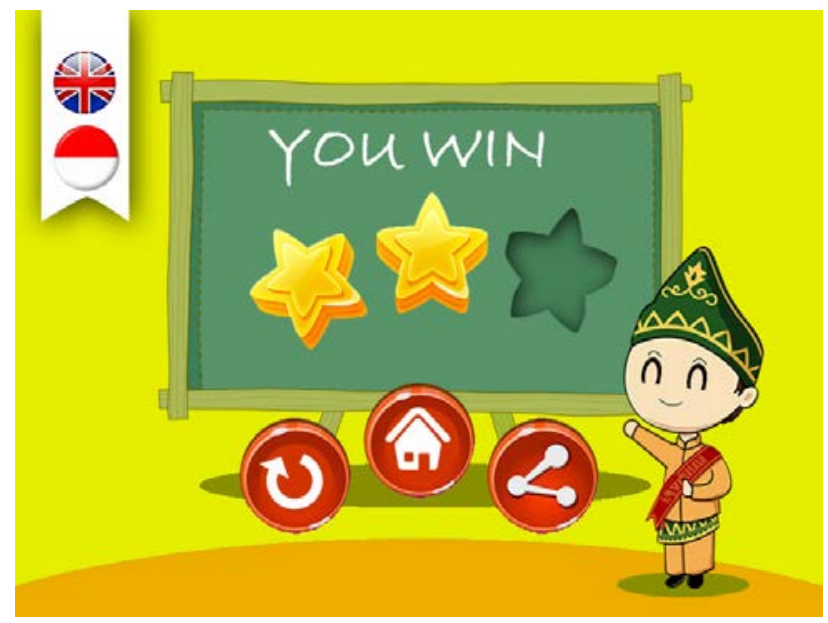

Fig7. Character is Sad When Player Lose

All these emoticons are made with the intention of making the game interface more interacting with the children's players. So the children who play this edu-game feel accompanied by the presence of game agents.

\section{B. Beta Testing}

Beta testing is a live test application in an environment that cannot be controlled by the developer[15,17,18]. Trials were conducted in the form of a simple questionnaire filled by teachers and students of Elementary School of Muhammadiyah 1. In this study, trials were conducted on 10 teachers and 40 students, which presented 5 questions that refer to the gameplay and role of game agent. Questionnaire questions are made as simple as possible so that students can also fill them out.

Table 1. Result of Beta Testing

\begin{tabular}{lcccc}
\hline \multicolumn{1}{c}{ Question } & \multicolumn{3}{c}{ Respondent's Questions } & TOTAL \\
\hline & Good & Average & Poor & \\
\hline \hline $\begin{array}{l}\text { How is character } \\
\text { design? }\end{array}$ & 7 & 3 & 0 & 10 \\
$\begin{array}{l}\text { How is the interface } \\
\text { view of this }\end{array}$ & 7 & 2 & 1 & 10 \\
$\begin{array}{l}\text { application? } \\
\begin{array}{l}\text { How is the learning } \\
\text { content? }\end{array}\end{array}$ & 6 & 3 & 1 & 10 \\
$\begin{array}{l}\text { How is audio and } \\
\text { music on this game? }\end{array}$ & 6 & 2 & 2 & 10 \\
$\begin{array}{l}\text { How is gameplay of } \\
\text { this game? }\end{array}$ & 8 & 1 & 1 & 10 \\
\hline \hline \multicolumn{1}{c}{ Total Answer } & 34 & 11 & 5 & $\mathbf{5 0}$ \\
\hline
\end{tabular}

From the results of beta testing in table 1, we can determine the weight of the calculation for the answer "less" has a weight of 1 , for the answer "enough" with weight 2 , and the answer "good" with weight 3 . Then we can calculate the average percentage of respondents:

$$
\bar{x}=\frac{34 \times 3+11 \times 2+5 \times 1}{50 \times 3} \times 100=86 \%
$$

Based on the percentage acquisition the percentage is $86 \%$, then the "Ulun Smart-Kid" edu-game is acceptable because the presentation of the value obtained, above the minimum percentage of $50 \%$ (above enough), and close to $100 \%$ (very good).

\section{Conclusion}

The results of this research conclude that, It has been built edu-game "Ulun Smart-Kid" learning media local content of Banjar language in the form of letter puzzle game. Application development is done according to the stage of multimedia development, ranging from conceptualizing gameplay to application distribution. Bring game agent as a child chaperone character to play. Finite State Machine applied to the game agent, making funny characters in the game can 
interact according to the action-reaction logic of the player's playing style. This is what makes educational games more interactive to children.

\section{Acknowledgment}

This research is funded by Directorate General of Strengthening for Research and Development and Ministry of Research, Technology and Higher Education of the Republic of Indonesia according the Research Contract in Fiscal Year of 2020

\section{References}

[1] Fouberg, E. H., \& Murphy, A. B. (2020). Human geography: people, place, and culture. John Wiley \& Sons.

[2] Basari, A. (2014). Penguatan Kurikulum Muatan Lokal dalam Pembelajaran di Sekolah Dasar. Prosiding Ilmu Pendidikan, 1(1).

[3] Sunarto, E., Mukarto, F. X., Bismoko, J., \& Dewi, N. (2018). Trilingual Textualization to Deliver Indonesian Local Cultures to High School Students. LLT Journal: A Journal on Language and Language Teaching, 21(1), 82-93.

[4] Zein, S. (2020). Language policy in superdiverse Indonesia. Routledge.

[5] Syahidi, A., Supianto, A., \& Tolle, H. (2019). Design and Implementation of Bekantan Educational Game (BEG) as a Banjar Language Learning Media.

[6] Grimm, C. M., Lee, H., Smith, K. G., \& Smith, K. G. (Eds.). (2006). Strategy as action: Competitive dynamics and competitive advantage. Oxford University Press.

[7] Pukeng, A. F., Fauzi, R. R., Andrea, R., Yulsilviana, E., \& Mallala, S. (2019, October). An intelligent agent of finite state machine in educational game "Flora the Explorer". In Journal of Physics: Conference Series (Vol. 1341, No. 4, p. 042006). IOP Publishing.

[8] Mandziuk, J. (2010). Knowledge-free and learning-based methods in intelligent game playing (Vol. 276). Heidelberg: Springer.

[9] Gerber, A., \& Götz, U. (Eds.). (2020). Architectonics of Game Spaces: The Spatial Logic of the Virtual and Its Meaning for the Real (Vol. 50). transcript Verlag.

[10] Rabin, S. (2019). Game AI Pro 360: Guide to Architecture. CRC Press.

[11] Rachman, A. Suhartono, V. dan Purwanto,Y. 2010. Intelligent Agent Animation Face For Guess Game of Word with Finite State Machine method. Jurnal Teknologi Informasi. 6 (1): 9-17.

[12] Andrea, R. 2013. Object Position Randomization Technique "Find Me! - The Game. Proceeding SENAIK. 1 November 2013, Samarinda, Indonesia. pp. 301-303.

[13] Andrea, R. 2015. Game Arena Randomization Technique "Find Me! - Bumi Etam” with the technique of Shuffle Random. Proceeding SENATKOM. 23 September 2015, Padang, Indonesia. pp. 823-827.

[14] Savov, S. A., Antonova, R., \& Spassov, K. (2019). Multimedia applications in education. In Smart Technologies and Innovation for a Sustainable Future (pp. 263-271). Springer, Cham.

[15] Aleem, S., Capretz, L. F., \& Ahmed, F. (2016). Game development software engineering process life cycle: a systematic review. Journal of Software Engineering Research and Development, 4(1), 6.

[16] Savov, S. A., Antonova, R., \& Spassov, K. (2019). Multimedia applications in education. In Smart Technologies and Innovation for a Sustainable Future (pp. 263-271). Springer, Cham.

[17] Jarzabek, S., Poniszewska-Marańda, A., \& Madeyski, L. (Eds.). (2020). Integrating Research and Practice in Software Engineering. Springer.

[18] Bécares, J. H., Valero, L. C., \& Martín, P. P. G. (2017). An approach to automated videogame beta testing. Entertainment Computing, 18, 79-92. 


\section{Authors' Profiles}

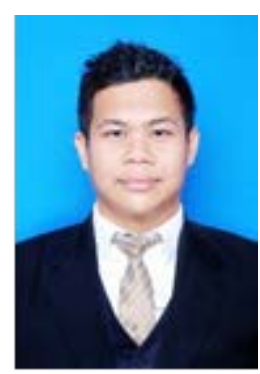

Reza Andrea, born in Samarinda on June 5th, 1989, holds a Bachelor of Computer from Mulawarman University and a Master degree in Computer from STMIK Eresha Jakarta. Active as a researcher and author fields of Programming, Multimedia Application, and Games. Reza Andrea is a lecturer in Software Engineering Technology (TRPL) Samarinda State Polytechnic Agriculture since 2019 and Expert Staff in Research Department of STMIK Widya Cipta Dharma since 2015.

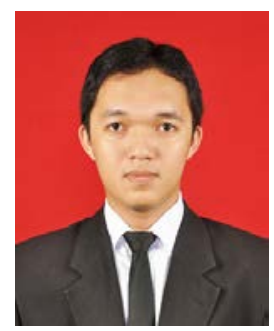

Asep Nurhuda is a lecture of Informatics Engineering in STMIK Widya Cipta Dharma Samarinda since 2013. His research interests include Computer Network, Computer Security, and Data Mining. Now he is Head of Informatics Engineering Department in STMIK Widya Cipta Dharma.

How to cite this paper: Reza Andrea, Asep Nurhuda. " Developing Edu-Game "Ulun Smart-Kid” Learning Media of Banjar Language and Game Agent with Finite State Machine Model ", International Journal of Education and Management Engineering (IJEME), Vol.10, No.5, pp.10-16, 2020. DOI: 10.5815/ijeme.2020.05.02 